\title{
Comparison Between Efficacy of Methylprednisolone and Triamcinolone in Intra Articular Injection for Osteoarthritis Pain Relief
}

\author{
Urwah Ehsan ${ }^{1} \quad$ Muhammad Umair ${ }^{2}$ Muhammad Azeem Gulzar ${ }^{3}$ \\ 1.House Officer, Bahawal Victoria Hospital, Bahawalpur \\ 2.House Officer, Mayo Hospital Lahore \\ 3.House Officer, Nishtar Hospital Multan
}

\begin{abstract}
Objective: To compare the effect of two different corticosteroid regimens methylprednisolone acetate and triamcenolone acetate in bilateral and symmetrical knee osteoarthritis (OA) pain relief. Study Design: A Randomize Control Trial. Place And Duration of Study: Department of Anaesthesia, Intensive care and Pain Management Nishtar Hospital, Multan, Bahawal Victoria Hospital and Mayo Hospital, Lahore from 1 November 2017 to 30 October 2018. Methodology: After getting ethical approval from hospital ethical committee and informed consent from patients to be included in study. Total 100 patients were enrolled in study through non probability consecutive sampling technique, and all patients were divided in two equal groups randomly using lottery method. Data was collected on pre designed Performa. Statistical analysis was done by using SPSS version 24 for all variables, mean and SD presentation for continuous data like age and VAS score, WOMAC score and frequency percentage presentation was given for categorical data like gender. $\mathrm{P}$ value $\leq 0.05$ was considered as significant. Results: Total 100 patients were included, in this study. The mean age and BMI of the patients was $60.33 \pm 2.61$ years and $27.06 \pm 2.42 \mathrm{~kg} / \mathrm{m}^{2}$ respectively. A significant decrease in VAS score for both knees (right and left) was observed after intra articular injection bilaterally. Measurements were done at 2, 4, 8, 12 and 24 weeks after injection administration $(\mathrm{p}<0.005)$. Conclusion: Results of our study revealed that intra articular injection is an effective mode of treatment when used for the management of osteoarthritis knee pain $(p<0.005)$. when we compared two steroid regimens Methylprednisolone and Triamcenolone it was observed that there is no significant difference among both groups, both are equally effective.
\end{abstract}

Keywords: Intra-aticular injection, Triamcenolone acetate, Methylprednisolone, Osteoarthritis.

DOI: $10.7176 / \mathrm{JMPB} / 62-01$

Publication date: December $31^{\text {st }} 2019$

\section{Introduction}

Knee pain in adult age is more probably due to the osteoarthritis OA, it reduces the quality of life and a continuous disability is the fate of person ${ }^{1,2}$. Main goal of such patients is control of pain with conservative management, exercise, physical therapy, medication and weight loss ${ }^{3}$. Surgical management also indicated in such patients but when disease in advance stages. American collage of advance rheumatology indicated intraarticular injection for its treatment and consider as a part of conservative management of knee osteoarthritis ${ }^{4}$. Mechanism of action of thus injection is not yet clear but it is reported that corticosteroids inhibits the release of leukocytes in synovial fluid and prevent the release of prostaglandins and interleukins ${ }^{5}$.

Clinical effectiveness of this injection was reported in many studies. Main concern of this treatment is cartilage destruction which is reported as progression in some studies, few reports shows reduction in progression of cartilage destruction ${ }^{6,7}$. Results of this corticosteroid injection are not consistent, short term benefits also reported in literature (about four weeks). On other hand some studies on this topic reported 24 weeks effect ${ }^{8}$. Some clinical trials on comparison of different corticosteroids are also available for intra articular injection ${ }^{9}$.

Along with these benefits some adverse effects and perceived efficacy are the main concern of osteoarthritis especially in knee osteoarthritis ${ }^{10}$. Among corticosteroids of intra articular injection triamcinolone hexacetonide and methylprednisolone acetate are common. Over more than of one third people of more than 65 years of age suffered from osteoarthritis who presents with pain which most common presenting complaint of patients ${ }^{11,12}$. Aim of our study is to compare two different types of drugs used in intra articular injections.

\section{Methodology}

This randomized control trial was completed Department of Anaesthesia, Intensive care and Pain Management Nishtar Hospital, Multan, Bahawal Victoria Hospital and Mayo Hospital, Lahore from 1 November 2017 to 30 October 2018. Study was started after ethical approval from ethical review board of hospital. Informed consent was obtained from patients as per hospital rules. Sampling technique used was non probability consecutive sampling and CI of 95 , power of $80 \%$ with mean VAS score after treatment in both groups was $7.7 \pm 1.3$ vs $7.5 \pm$ 
1.5 right and left knee was used to calculate sample size.

Pain of patients was assessed by using visual analogue score scale (VAS). Patients presented in Pain clinic outdoor with bilateral knee pain and baseline pain score was noted. Radiological investigation for grade 3 OA was done as per Kellgren Lawrence classification and who were unsatisfied from previous conservative mode of treatment were included in the study. Patients with history of previous intra articular injection, unstable joint, secondary arthritis, diabetes, any malignant cancer, BMI more than 30 and who were contraindicated to injections like presence of infection, on anti coagulant therapy and allergic to drug used were excluded from the study.

In our study we used methylprednisolone acetate in right knee and triamcinolone hexacetonide in left knee of same patient. Lateral position for injection was used in sitting position with 90 degree knee flexion. Skin was cleaned with pyodine swab before injection, no anesthetic was given before procedure. Methylprednisolone acetate $40 \mathrm{mg} 1 \mathrm{ml}$ was mixed with $3 \mathrm{ml}$ of lidocain $1 \%$ and triamcinolone hexacetonide $40 \mathrm{mg} 2 \mathrm{ml}$ mixed with lidocaine $1 \%$ with $22 \mathrm{G}$ needle. A third person who is unaware of study was appointed to evaluate the study variables. Before injection patients were evaluated and than at $2^{\text {nd }}$ week, $4^{\text {th }}$ week, $8^{\text {th }}$ week, 12 th week and $24^{\text {th }}$ week. Severity of pain was assessed by using VAS score and functionality of joint was assessed by using WOMAC scale. All possible complications and side effects were evaluated and recorded on pre designed Performa.

Statistical analysis was done by using SPSS version 24 for all possible variables, mean and SD presentation for continuous data like age and VAS score, WOMAC score and frequency percentage presentation was given for categorical data like gender. P value less than or equal to 0.05 was considered as significant.

\section{Results}

Overall 100 patients were included, in this study. The mean age and BMI of the patients was $60.33 \pm 2.61$ years and $27.06 \pm 2.42 \mathrm{~kg} / \mathrm{m}^{2}$ respectively. (Table. 1). At first admission, the mean VAS score for the right knee, the left knee and WOMAC was 8.04 $\pm 2.1,7.37 \pm 1.5$ and $68.64 \pm 3.0$ respectively. At $2^{\text {nd }}$ week, the mean VAS score for the right knee, the left knee and WOMAC was $2.34 \pm 1.3,2.07 \pm 1.1$ and $30.90 \pm 2.1$ respectively. At $4^{\text {th }}$ week, the mean VAS score for the right knee, the left knee and WOMAC was 2.23 $\pm 1.3,2.22 \pm 1.1$ and $33.78 \pm 3.8$ respectively. At $8^{\text {th }}$ week, the mean VAS score for the right knee, the left knee and WOMAC was4.1 \pm 1.5 , $3.8 \pm 1.1$ and $47.1 \pm 2.8$ respectively. At $12^{\text {th }}$ week, the mean VAS score for the right knee, the left knee and WOMAC was $5.5 \pm 1.1,5.1 \pm 1.13$ and $58.1 \pm 2.19$ respectively. While, at $24^{\text {th }}$ week, the mean VAS score for the right knee, the left knee and WOMAC was $5.9 \pm 1.43,5.66 \pm 1.33$ and $60.80 \pm 2.49$ respectively. A significant decrease in VAS score for both knees (right and left) was observed after intra articular injection bilaterally. Measurements of was done at 2, 4, 8, 12 and 24 weeks after injection administration $p<0.005$ (Table. 2).

Graphical representation of mean VAS scores was after injection with methylprednisolone acetate, triamcinolone hexacetonide were given in Figure. 1 and II. Similarly graphical represention of mean WOMAC scores for both knees was given in figure. III).

Table. 1

Demographic Characteristics

\begin{tabular}{|c|c|}
\hline Variables & Mean \pm S.D \\
\hline Age $($ years $)$ & $\mathbf{6 0 . 3 3} \pm 2.61$ \\
\hline BMI $\left(\mathrm{kg} / \mathrm{m}^{2}\right)$ & $\mathbf{2 7 . 0 6} \pm 2.42$ \\
\hline
\end{tabular}

Table. II

Mean VAS scores of right and left knee and mean WOMAC scores of the patients

\begin{tabular}{|c|c|c|c|c|c|c|c|c|}
\hline \multicolumn{3}{|c|}{ First Admission } & \multicolumn{3}{c|}{$2^{\text {nd }}$ week } & \multicolumn{3}{c|}{$4^{\text {th }}$ week } \\
\hline VAS R & VAS L & WOMAC & VAS R & VAS L & WOMAC & VAS R & VAS L & WOMAC \\
\hline $\mathbf{8 . 0 4} \pm 2.1$ & $7.37 \pm 1.5$ & $\mathbf{6 8 . 6 4} \pm 3.0$ & $2.34 \pm 1.3$ & $2.07 \pm 1.1$ & $30.90 \pm 2.1$ & $2.23 \pm 1.3$ & $2.22 \pm 1.1$ & $33.78 \pm 3.8$ \\
\hline \multicolumn{3}{|c|}{$8^{\text {th }}$ week } & \multicolumn{3}{c|}{$12^{\text {th }}$ week } & \multicolumn{3}{c|}{$24^{\text {th }}$ week } \\
\hline VAS R & VAS L & WOMAC & VAS R & VAS L & WOMAC & VAS R & VAS L & WOMAC \\
\hline $4.1 \pm 1.5$ & $3.8 \pm 1.1$ & $47.1 \pm 2.8$ & $5.5 \pm 1.1$ & $5.1 \pm 1.13$ & $58.1 \pm 2.19$ & $5.9 \pm 1.43$ & $5.66 \pm 1.33$ & $60.80 \pm 2.49$ \\
\hline
\end{tabular}


Figure. 1

Mean VAS score in methylprednisolone acetate after injection

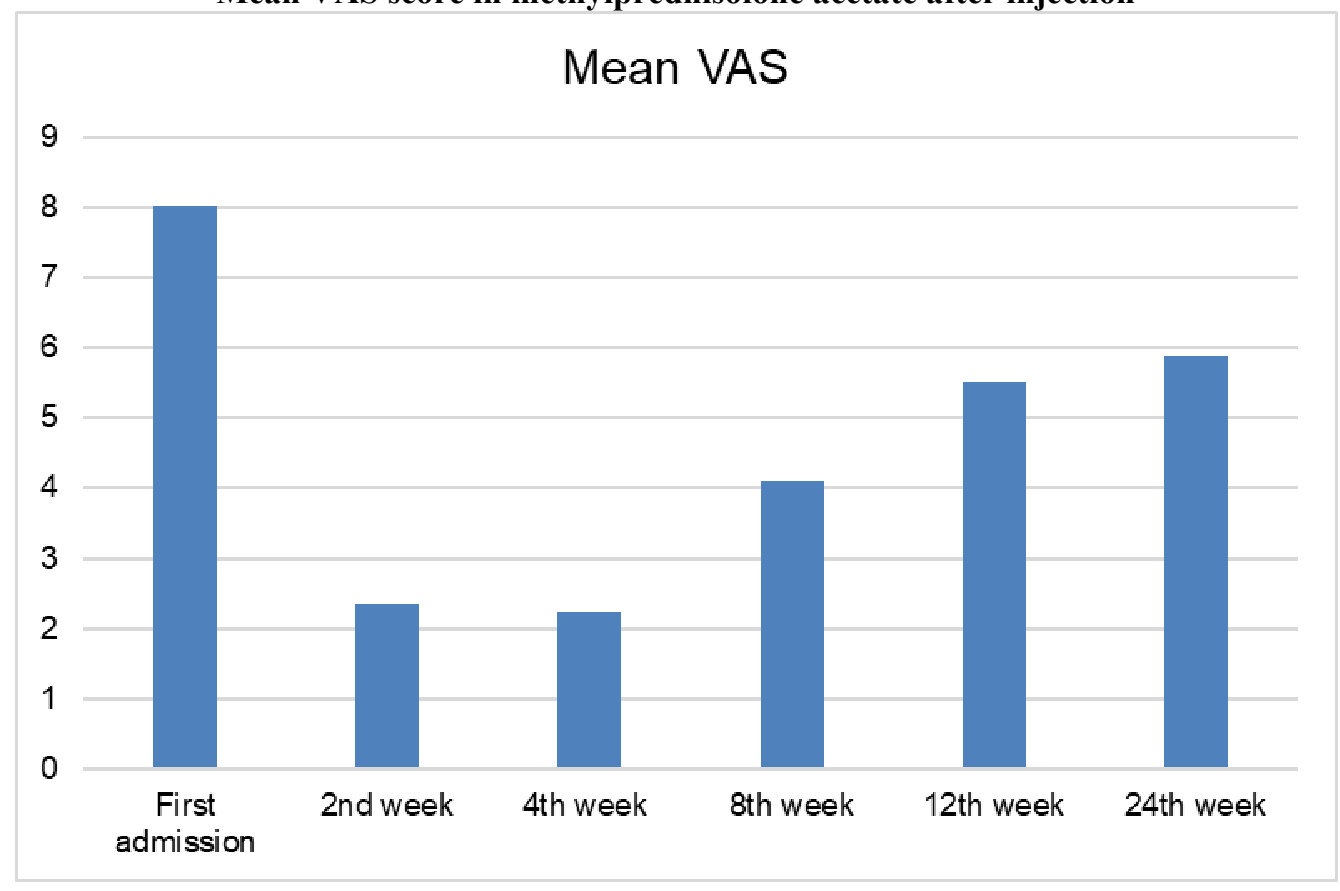

Figure. II

Mean VAS score after injection in triamcinolone hexacetonide

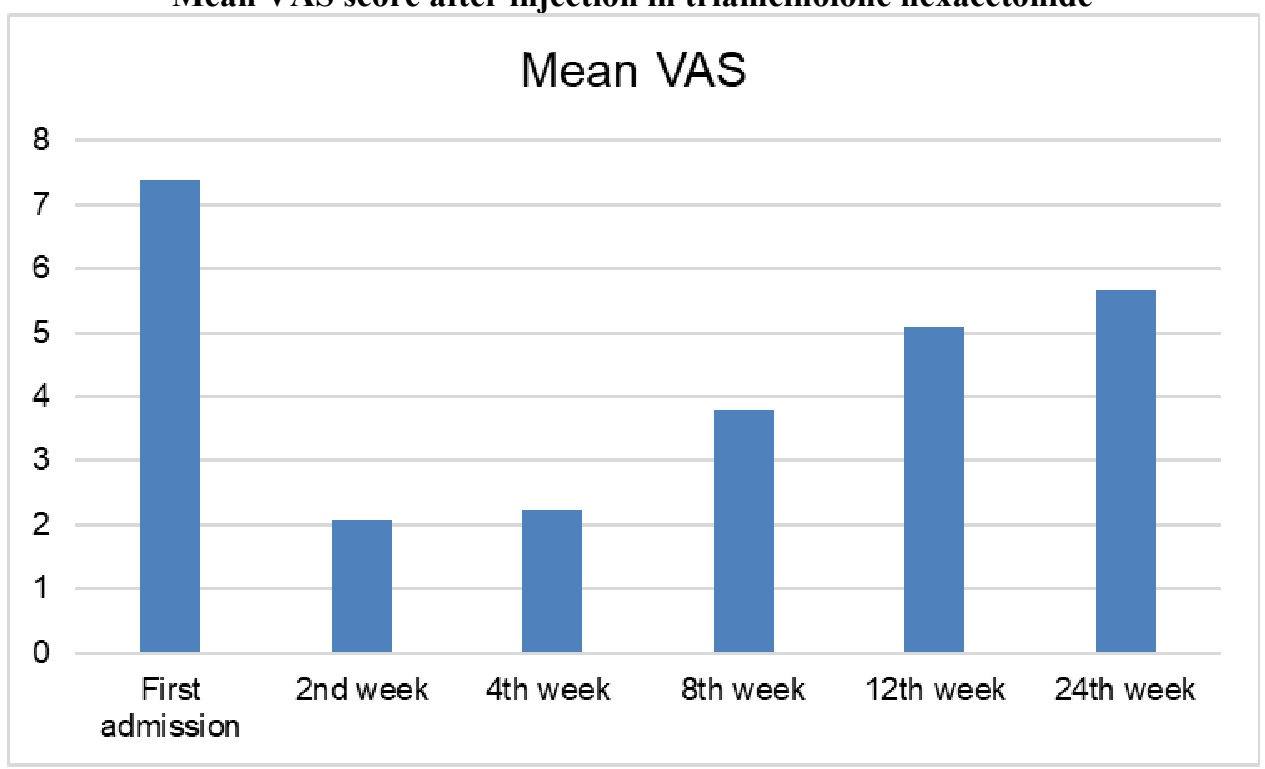


Figure. III

Mean of WOMAC Score in both knees

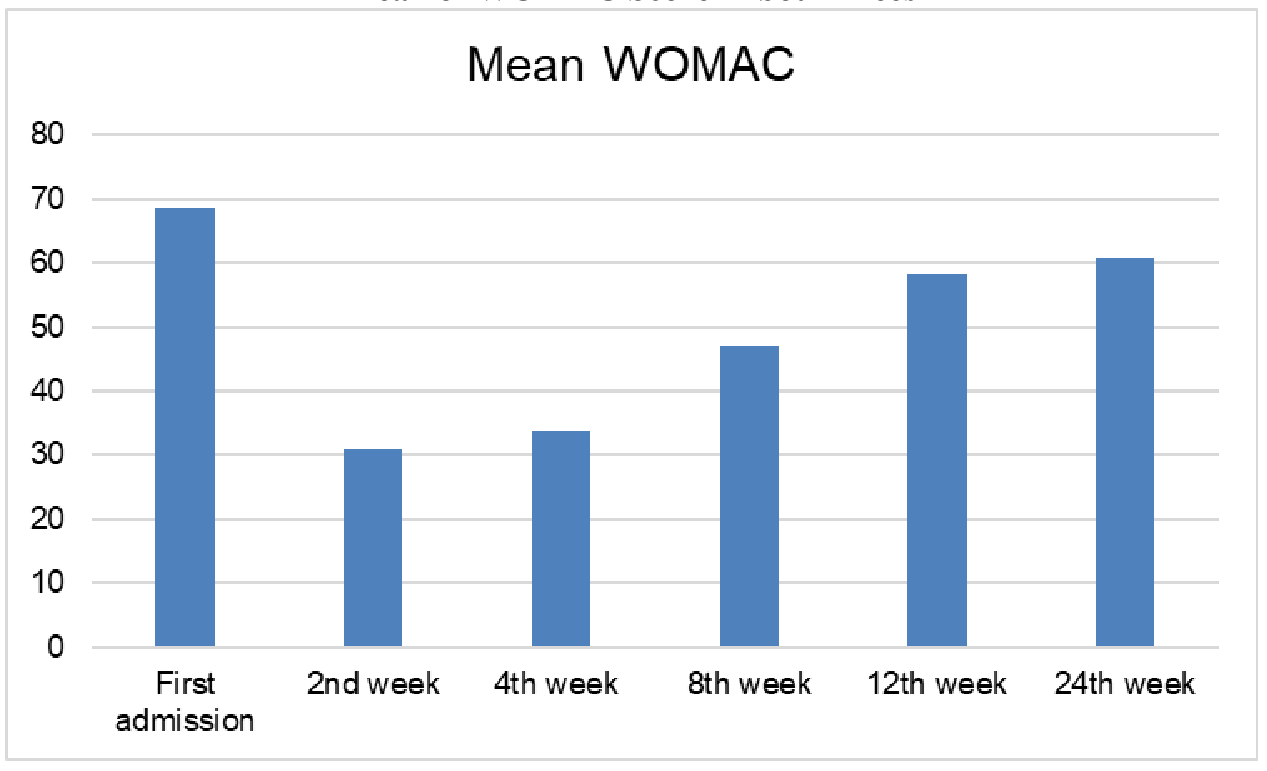

\section{Discussion}

Results of our study showed significant decrease in VAS score for both knees (right and left) was observed after intra articular injection bilaterally. Measurements of was done at 2, 4, 8, 12 and 24 weeks after injection administration $\mathrm{p}<0.005$. In comparison between the groups there was not a remarkable difference, both regimens are almost equally effective.

In a study conducted by Arroll B et al ${ }^{13}$ reported that intra articular injection in the treatment of knee pain after osteoarthritis is an effective mode of treatment and have reliable effects on quality of life. In another study conducted by Godwin $\mathrm{M}$ et al ${ }^{14}$ reported similar findings that intra articular injection is an effective and useful technique for the relief of osteoarthritis knee pain. These two studies are comparable with our results.

In a double blind study of placebo control was conducted by Raynauld et al ${ }^{15}$ and reported that not only a single use but repetitive use of intra articular injection is useful for the relief of osteoarthritis symptoms, it will never destroy the anatomical position and structure of knee. In a study Pyne et al ${ }^{16}$ compared triamcenolone and methylprednisolone in intra articular injection and reported that triamcenilone is more effective than methylprednisolone in pain relief.

While in study Yavuz et al ${ }^{17}$ reported that methylprednisolone is more effective as compared to triamcenolone when their efficacy was compared in intra articular injection for relief of osteoarthritis pain until 6 weeks of injection administration. In a study conducted by Buyuk AF et $\mathrm{al}^{8}$ reported that there is no difference in effectiveness of both corticosteroids regimens in knee pain relief.

Recommended dose of methylprednisolone in intra articular injection is 20 to $80 \mathrm{mg}$ and for triamcenolone 20-40 mg ${ }^{18,19}$. In our study we use similar dose $40 \mathrm{mg}$ for both regimens as used by Buyuk et al ${ }^{8}$ in his study. Jain $\mathrm{P}$ et al ${ }^{20}$ conducted a study on this topic and reported that intra articular injection for pain relief is an effective and use of corticosteroid especially methylprednisolone is more beneficial as compared other regimens.

In another study by Shikhar et $\mathrm{al}^{21}$ reported a significant improvement in WOMAC score in methylprednisolone group as compared to triamcinolone. VAS score is also showing good effects as compared to other regimens when compared to other corticosteroids. This study is comparable with our study.

Another study conducted by Smith et $\mathrm{al}^{22}$ reported similar findings as methylprednisolone is more effective as compare to other regimens of corticosteroids when used in intra articular injection for relief of osteoarthritis pain. We can also compare this study with our study.

\section{Conclusion}

Results of our study revealed that intra articular injection is an effective mode of treatment when used for the management of osteoarthritis knee pain $(\mathrm{p}<0.005)$. when we compared two steroid regimens Methylprednisolone and Triamcenolone it was observed that there is not a significant difference among both groups, both are equally effective.

\section{References}

1. Healey EL, Main CJ, Ryan S, et al. A nurse-led clinic for patients consulting with osteoarthritis in general 
practice: development and impact of training in a cluster randomised controlled trial. BMC Family Practice. 2016;17:173.

2. Kelli D. Allen, Dennis Bongiorni, Hayden B. Bosworth, Cynthia J et al. Individual Physical Therapy for Veterans With Knee Osteoarthritis: Randomized Clinical Trial, Physical Therapy. 2016;96(5):597-608.

3. Brembo EA, Kapstad H, Eide T, Månsson L, Van Dulmen S, Eide H. Patient information and emotional needs across the hip osteoarthritis continuum: a qualitative study. BMC Health Services Research. 2016;16:88.

4. Alkatan M, Baker JR, Machin DR, Park W, Akkari AS, Pasha EP. Improved Function and Reduced Pain after Swimming and Cycling Training in Patients with Osteoarthritis. J Rheumatol. 2016;43(3):666-672.

5. Cutolo M, Berenbaum F, Hochberg M, Punzi L, Reginster JY. Commentary on recent therapeutic guidelines for osteoarthritis. Semin Arthritis Rheum. 2015;44(6):611-7.

6. Papandony MC, Chou L, Seneviwickrama M, Cicuttini FM, Lasserre K, Teichtahl AJ. Patients' perceived health service needs for osteoarthritis (OA) care: a scoping systematic review. Osteoarthritis Cartilage. 2017;25(7):1010-1025.

7. Jong-Uk Mun, Hyung Rae Cho, Young Soon Choi, Young Uk Kim. Effect of multiple intra-articular injections of polynucleotides on treatment of intractable knee osteoarthritis. Medicine. 2017;96:49:p9127.

8. Buyuk AF, Kilinc E, Camurcu IY, Camur S, Ucpunar H, Kara A. Compared efficacy of intra-articular injection of methylprednisolone and triamcinolone. Acta Ortopedica Brasileira. 2017;25(5):206-208.

9. Kumar A, Dhir V, Sharma S, Sharma A, Singh S. Efficacy of Methylprednisolone Acetate Versus Triamcinolone Acetonide Intra-articular Knee Injection in Patients With Chronic Inflammatory Arthritis: A 24-Week Randomized Controlled Trial. Clin Ther. 2017;39(1):150-158.

10. Ravelli A, Davì S, Bracciolini G, Pistorio A, Consolaro A, van Dijkhuizen EHP. Intra-articular corticosteroids versus intra-articular corticosteroids plus methotrexate in oligoarticular juvenile idiopathic arthritis: a multicentre, prospective, randomised, open-label trial. Lancet. 2017;389(10072):909-916.

11. Lomonte AB, de Morais MG, de Carvalho LO, Zerbini CA. Efficacy of Triamcinolone Hexacetonide versus Methylprednisolone Acetate Intraarticular Injections in Knee Osteoarthritis: A Randomized, Double-blinded, 24-week Study. J Rheumatol. 2015;42(9):1677-1684.

12. Garg N, Perry L, Deodhar A. Intra-articular and soft tissue injections, a systematic review of relative efficacy of various corticosteroids. Clin Rheumatol. 2014;33(12):1695-706.

13. Arroll B, Goodyear-Smith F. Corticosteroid injections for osteoarthritis of the knee: meta-analysis. BMJ. 2004;328(7444):869.

14. Godwin M, Dawes M. Intra-articular steroid injections for painful knees. Systematic review with metaanalysis. Can Fam Physician. 2004;50:241-8.

15. Raynauld JP, Buckland-Wright C, Ward R, Choquette D, Haraoui B, Martel- -Pelletier J, et al. Safety and efficacy of long-term intraarticular steroid injections in osteoarthritis of the knee: a randomized, doubleblind, placebo-controlled trial. Arthritis Rheum. 2003;48(2):370-7.

16. Pyne D, Ioannou $\mathrm{Y}$, Mootoo R, Bhanji A. Intra-articular steroids in knee osteoarthri- tis: a comparative study of triamcinolone hexacetonide and methylprednisolone acetate. Clin Rheumatol. 2004;23(2):116-20.

17. Yavuz U, Sökücü S, Albayrak A, Oztürk K. Efficacy comparisons of the intra- articular steroidal agents in the patients with knee osteoarthritis. Rheumatol Int. 2012;32(11):3391-6.

18. Habib GS. Systemic effects of intra-articular corticosteroids. Clin Rheumatol. 2009;28(7):749-56.

19. Pfenninger JL. Injections of joints and soft tissue: Part II. Guidelines for specific joints. Am Fam Physician. 1991;44(5):1690-701.

20. Jain P, Jain SK. Comparison of Efficacy of Methylprednisolone and Triamcinolone in Osteoarthritis of the Knee: A Prospective, Randomized, Double-Blind Study. Int J Sci Stud 2015;3(4):58-62.

21. Shikhar P, Pandey JK, Narayan A, Mahajan R. A prospective clinical evaluation between intra-articular injections of methyl prednisolone and triamcinolone in osteoarthritis of knee based on the efficacy, duration and safety. Int J Curr Microbiol Appl Sci 2013;2:369-81.

22. Smith MD, Wetherall M, Darby T, Esterman A, Slavotinek J, RobertsThomson P, et al. A randomized placebo-controlled trial of arthroscopic lavage versus lavage plus intra-articular corticosteroids in the management of symptomatic osteoarthritis of the knee. Rheumatology (Oxford) 2003;42:1477-85. 